\title{
Paradoxical response of sphincter of Oddi to intravenous injection of cholecystokinin or ceruletide. Manometric findings and results of treatment in biliary dyskinesia
}

\author{
P ROLNY, A ÄRLEBÄCK, P FUNCH-JENSEN, A KRUSE, \\ J RAVNSBAECK AND G JÄRNEROT
}

From the Departments of Medicine, Division of Gastroenterology and Clinical Physiology, Örebro Medical Center Hospital, Örebro, Sweden and Surgical Gastroenterology Department L, Kommunehospitalet, University of Aarhus, Denmark

SUMMARY Sixty two patients with a clinical suspicion of biliary dyskinesia were investigated with endoscopic manometry of the sphincter of Oddi before and after intravenous injection of cholecystokinin or ceruletide. In 52 patients injection was followed by decreased pressure in the sphincter of Oddi; 43 of these had normal prestimulatory values (group I), while the values were raised in the other nine patients (group II). A paradoxical response to intravenous injection was observed in 10 women (group III): increased baseline sphincteric pressure occurred in eight and increase in the amplitude of phasic contractions in four patients. The prestimulatory sphincteric pressure was raised in five and normal in the remaining patients. Eight patients were treated with papillotomy (seven) or balloon dilatation of the sphincter (one). They experienced relief of pain during a follow up period of 11-16 months. Intravenous injection of cholecystokinin or ceruletide may disclose a special type of biliary dyskinesia even in patients with normal prestimulatory manometric findings. Hormone injection increases the diagnostic yield of endoscopic manometry in patients suspected of biliary dyskinesia.

A paradoxical increase in the basal sphincter of Oddi pressure after injection of cholecystokinin has recently been observed in five patients investigated on the suspicion of biliary dyskinesia. ${ }^{1}$ This may represent a new type of biliary dyskinesia as normally in man, cholecystokinin reduces or abolishes the sphincter of Oddi phasic contractions and causes a modest, but significant decrease in basal sphincter of Oddi pressure. ${ }^{2}$ Likewise ceruletide a synthetic analogue of caerulein elicits a powerful relaxing effect on sphincter of Oddi pressure activity. ${ }^{34}$

We carried out endoscopic manometry of sphincter of Oddi before and after injection of cholecystokinin or ceruletide in 62 patients with clinical suspicion of biliary dyskinesia. Ten of the patients

Address for correspondence: Peler Rolny. MI), Division of (iastrocnterologs. Department of Medicine, Orebro Medical (enter Hospital. S-701 85 Orebro. Sweden

Received for publication 22 April. 1986 showed a paradoxical increase in the sphincter of Oddi pressure after hormone injection; eight were submitted to papillotomy or balloon dilatation of the sphincter of Oddi. Thus in this paper we not only extend the previous observations, ${ }^{1}$ but also report our results of treatment in this new type of biliary dyskinesia.

\section{Methods}

PATIENTS

During 1984-1985 62 patients suffering from long standing episodic right upper quadrant pain were studied. Thorough laboratory investigations, oesophago-, gastro-, duodeno-scopy, endoscopic retrograde cholangio-pancreatography, pancreatic function tests as well as small bowel biopsy had showed normal results in all patients. To exclude or confirm the possibility of biliary dyskinesia as the cause of symptoms endoscopic manometry of the sphincter of Oddi was done before and after 
cholecystokinin or ceruletide injection in all patients.

The peroperative manometric technique as recently described in detail ${ }^{5}$ has been adjusted for endoscopic application. We used a triple lumen catheter (Arndorfer, Med Spec, USA) perfused by distilled water or sterile isotonic saline. The duodenal pressure was taken as zero reference. A duodenoscope (Olympus JF-1T) was used and the papilla was cannulated within five minutes in all cases. In four patients (MJ, A-KL, IK, MT), diazepam 5-20 mg was given intravenously immediately before the investigation as the only medication. The remaining patients also received $0.5 \mathrm{mg}$ atropin intramuscularly 60 minutes before the study.

The sphincter of Oddi pressure was registered for at least three minutes after a steady registration had been achieved. Thereafter cholecystokinin (Cholecystokinin ${ }^{\circledR}$, Kabi Vitrum, Sweden) 1 U/kg bodyweight or ceruletide (Ceruletide ${ }^{\circledR}$, Farmitalia, Italy) $0.3 \mu \mathrm{g} / \mathrm{kg}$ bodyweight was given intravenously as a pulse dose during 30 seconds. The maximal levels of basal pressure amplitude and frequency of phasic contractions during the period before the injection of cholecystokinin or ceruletide were compared with the maximal levels registered during a period of at least two (mean three) minutes after the beginning of the injection of the hormone. The manometric registration has always been done before ERCP.

\section{Results}

On the basis of the results of the manometric recording the patients could be divided into three groups, Table 1.

Table 1 Baseline sphincter of Oddi pressure (Blp, $\mathrm{mmHg}$ ), amplitude ( $\mathrm{Ampl}, \mathrm{mmHg}$ ) and frequency ( $\mathrm{Frq}$, waves/min) of phasic contractions before $(B)$ and after $(A)$ iv injection of cholecystokinin or ceruletide in the various groups of patients. $(n=62)$

\begin{tabular}{|c|c|c|c|c|}
\hline & & $\begin{array}{l}\text { Blp* } \\
\text { Mean (range) }\end{array}$ & $\begin{array}{l}\text { Ampl* } \\
\text { Mean (range) }\end{array}$ & $\begin{array}{l}F r q^{*} \\
\text { Mean (range) }\end{array}$ \\
\hline Group I & B & $14 \cdot 1(6-24)$ & $141(110-200)$ & $4 \cdot 5(3-8)$ \\
\hline$n=43$ & A & $8 \cdot 5(3-20)$ & $24(0-76)$ & $0 \cdot 7(0-2)$ \\
\hline Group II & B & $48 \cdot 2(24-84)$ & $228 \cdot 3(162-320)$ & $6 \cdot 6(4-10)$ \\
\hline $\mathrm{n}=9$ & A & $27 \cdot 1(4-55)$ & $32 \cdot 1(0-150)$ & $0.9(0-2)$ \\
\hline Group III & B & $43 \cdot 6(16-90)$ & $220 \cdot 8(88-401)$ & $5 \cdot 4(3-9)$ \\
\hline$n=10$ & A & $73 \cdot 4(20-140)$ & $258 \cdot 7(103-350)$ & $4 \cdot()(2-9)$ \\
\hline
\end{tabular}

${ }^{*}$ Mean values and range observed in healthy volunteers $(n=9)$ : Blp 11.3 (8-16). Ampl 110.5 (63-184), Frq 2.8 (1.3-4.6).
GROUP I

Forty three patients (one man, 42 women) with a mean age of 43.5 years (range 30-56) had a normal or only slightly abnormal prestimulatory manometric registration. All but two had had a cholecystectomy two to 16 years earlier (mean 6.1). The hormone injection induced a moderate decrease in baseline sphincter of Oddi pressure (Blp) and a profound inhibition of phasic contractions. In 30 of the patients the hormone injection caused abdominal discomfort, but none experienced distinct abdominal symptoms.

\section{GROUP II}

Nine patients (one man, eight women) with a mean age of 46.7 years (range 35-62) showed manometric abnormalities, mainly raised Blp indicating biliary dyskinesia. In seven cholecystectomy had been done five to 18 years before the study (mean $7 \cdot 4$ ). The hormone injection induced an inhibition of sphincter of Oddi pressure in all subjects. The Blp became normal in three patients whereas in spite of a marked decrease it remained above the reference limit in the remaining six. In six of the patients the hormone injection was followed by abdominal discomfort, but none experienced a distinct biliarylike abdominal pain. In two patients an endoscopic papillotomy was carried out. One of them improved and has remained symptom free 1.5 years after the intervention. The Blp values in this patient before and after the hormone injection were 84 and $20 \mathrm{mmHg}$ respectively. A second patient did not improve; Blp values were 28 and $20 \mathrm{mmHg}$ respectively. The phasic contractions were normal in both patients. The remaining seven patients in this group still have abdominal symptoms which are treated conservatively.

GROUP III

A paradoxical sphincter of Oddi response to the hormone injection was observed in 10 women aged 22-75 years (mean 43.7) who had had right upper quadrant pain for one to 20 (mean 5.7) years. All but one (A-KL) had had a cholecystectomy three to 20 years (mean $7 \cdot 1)$ earlier. The results are shown in detail in Table 2 and examples of the paradoxical sphincter of Oddi response are shown in Figures 1 and 2 .

The most common response was a rise of the Blp, which occurred in eight patients (MJ, IK, MT, AC, $\mathrm{JA}, \mathrm{LJ}, \mathrm{AW}, \mathrm{KM})$. Three of these patients (MJ, MT, JA) also showed an increase in amplitude of phasic contractions (arbitrarily defined as an increase of at least $30 \mathrm{mmHg}$ ) and in a further three patients (AC, LJ, AW) the amplitude remained unchanged. An additional patient (A-KL) in whom 

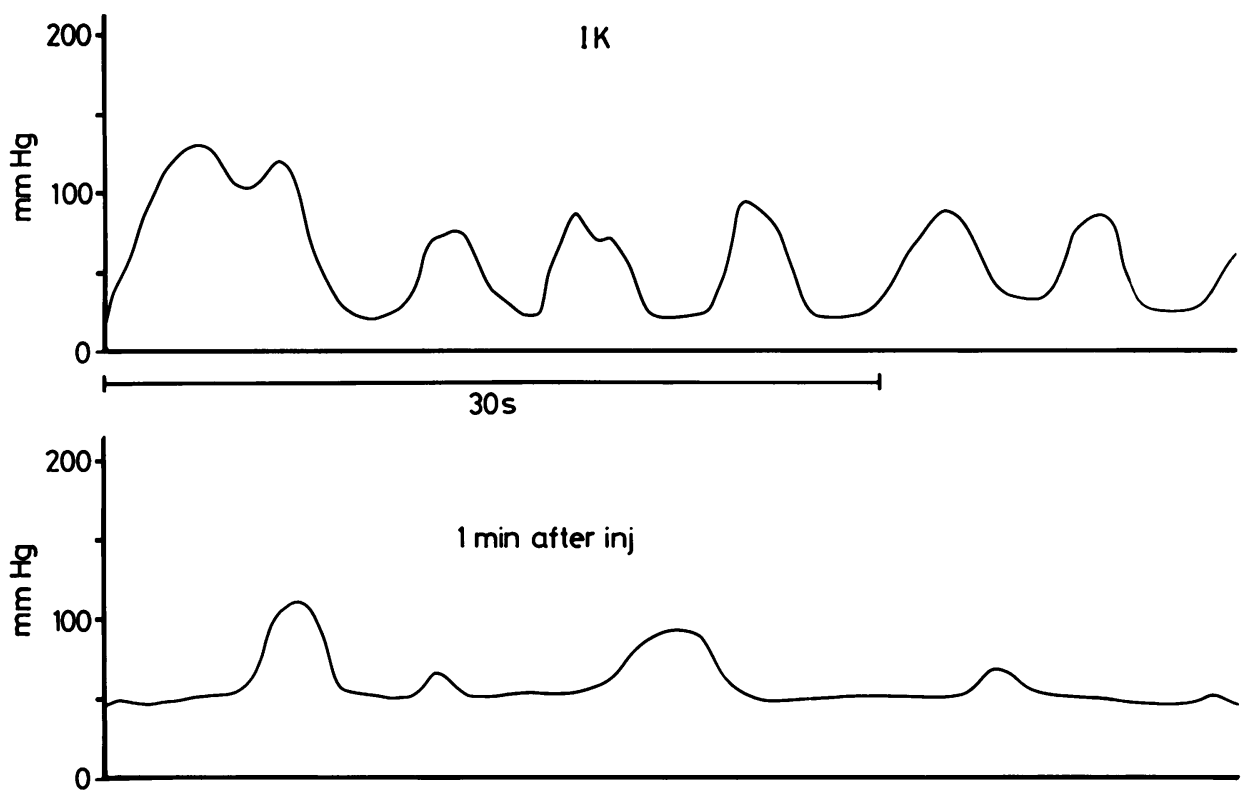

Fig. 1 Sphincter of Oddi activity before (upper record) and I minute after (lower record) cholecystokinin injection. Note the marked rise of baseline pressure.
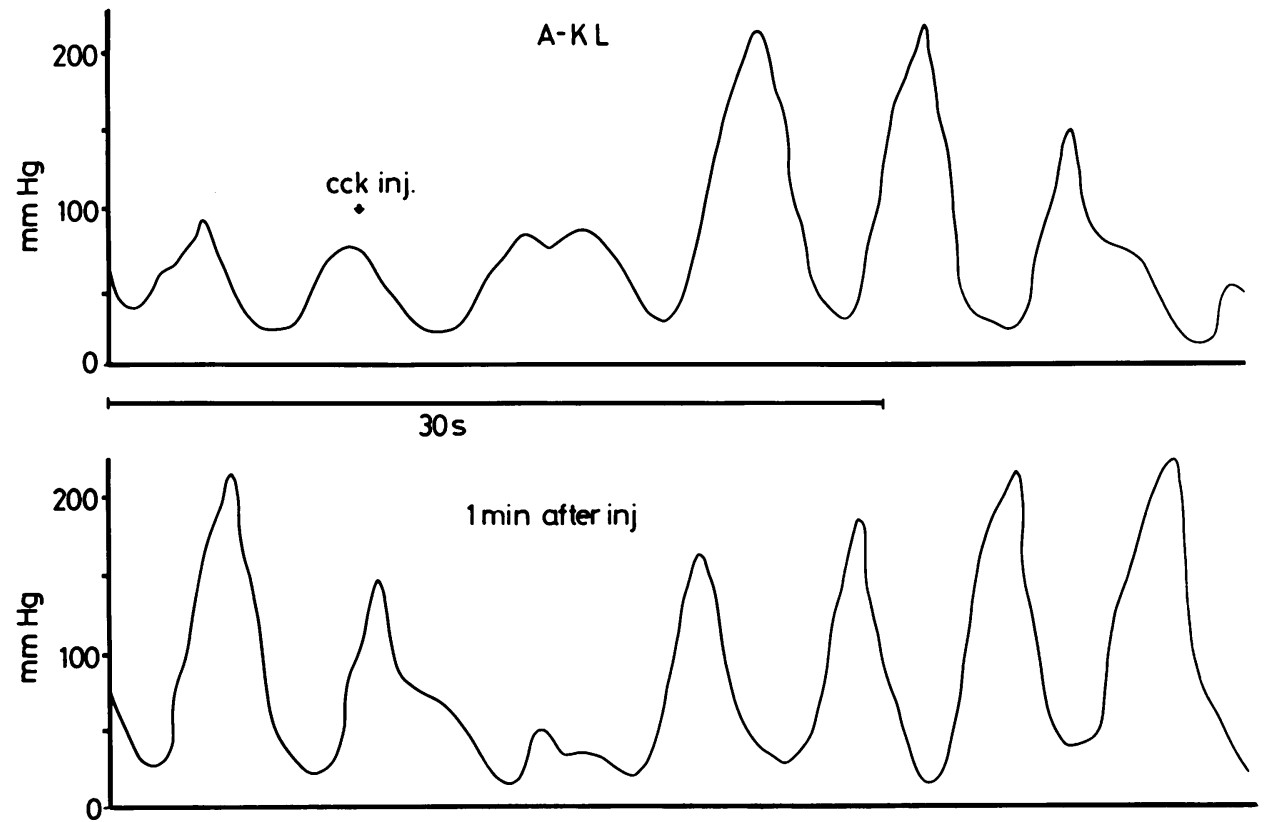

Fig. 2 Sphincter of Oddi activity before, during (upper record) and after (lower record) cholecystokinin injection. Note the marked rise of amplitude of phasic contractions. 
Table 2 Details in baseline sphincter of Oddi pressure (Blp, $\mathrm{mmHg}$ ), amplitude (Ampl, $\mathrm{mmHg}$ ) and frequency of phasic contractions (Frq, waves/min) before and after injection of cholecystokinin or ceruletide in patients with a paradoxical response

\begin{tabular}{|c|c|c|c|c|c|c|c|}
\hline \multirow[b]{2}{*}{ Patient } & \multicolumn{3}{|c|}{$\begin{array}{l}\text { Before hormone } \\
\text { injection }\end{array}$} & \multicolumn{3}{|c|}{$\begin{array}{l}\text { After hormone } \\
\text { injection }\end{array}$} & \multirow[b]{2}{*}{ Pain } \\
\hline & $B l p$ & Ampl & Frq & $B l p$ & Ampl & Frq & \\
\hline $\mathrm{MJ}^{*}$ & 16 & 88 & 4 & 34 & 218 & 4 & $\dagger$ \\
\hline A-KL ${ }^{*}$ & 22 & 105 & 7 & 20 & 250 & 9 & $\$$ \\
\hline $\mathrm{IK}^{*}$ & 18 & 120 & 6 & 45 & 103 & 2 & $\$$ \\
\hline $\mathrm{MT}^{\mathrm{ik}}$ & 20 & 154 & 9 & 30 & 306 & - & $\$$ \\
\hline $\mathrm{AC}^{\dagger}$ & 90 & 340 & 3 & 110 & 350 & 4 & $\$$ \\
\hline $\mathbf{J A} \div$ & 70 & 280 & 4 & 110 & 310 & 3 & $\doteqdot$ \\
\hline $\mathrm{LJ} t$ & 50 & 180 & 4 & 80 & 200 & 3 & $\doteqdot$ \\
\hline$A W \div$ & 50 & 300 & 4 & 140 & 320 & 4 & $\div$ \\
\hline $\mathrm{FC}^{+}$ & 80 & 240 & 9 & 85 & 180 & 3 & $\ddagger$ \\
\hline KM+ & 20 & 401 & 4 & 80 & 350 & 4 & + \\
\hline
\end{tabular}

${ }^{*}$ Cholecystokinin, †Ceruletide, $\Varangle$ Moderate pain. $\$$ Slight pain.

the slightly raised prestimulatory Blp remained unaffected by the hormone injection exhibited a marked increase in amplitude. In the remaining patient (FC) a normal inhibition of phasic contractions could be observed, but the markedly raised Blp did not decrease. An increase in frequency of phasic contractions has not been observed in any of the patients.

All patients experienced mild to moderate biliarytype symptoms during the hormone injection.

\section{CLINICAL OUTCOME}

Endoscopic papillotomy was carried out in seven of the patients whereas one had an endoscopic balloon dilatation of the sphincter, Table 3 . Complete relief

Table 3 Intervention and clinical outcome in patients with a paradoxical response to hormone injection

\begin{tabular}{lllll}
\hline Patient & $\begin{array}{l}\text { Inter- } \\
\text { vention }\end{array}$ & $\begin{array}{l}\text { Clinical } \\
\text { outcome }\end{array}$ & $\begin{array}{l}\text { Follow up } \\
\text { (month) }\end{array}$ & Remark \\
\cline { 1 - 2 } MJ & EPT & Symptom frec & $14^{*}$ & Relapse \\
A-KL & 0 & Unchanged & 16 & - \\
IK & EPT & Symptom free & 17 & - \\
MT & 0 & Unchanged & 5 & - \\
AC & EPT & Symptom frec & $11 \dagger$ & Repapillotomy \\
JA & EPT & Symptom frec & $12 \cdot 5 \dagger$ & Repapillotomy \\
LJ & EPT & Symptom frec & 15 & - \\
AW & EPT & Symptom frec & $13 \dagger$ & Repapillotomy \\
FC & EPT & Improved & $16 \dagger$ & Repapillotomy \\
KM & BD & Symptom frec & $15 \cdot 5$ & - \\
\hline
\end{tabular}

EPT Endoscopic papillotomy.

BD Balloon dilatation.

${ }^{*}$ Refers to interval papillotomy-relapse.

$+R$ efers to time after re-papillotomy. of symptoms was achieved in seven patients. The remaining patient (FC) improved, but was not symptom free, not even after repapillotomy. Three of the initially symptom free patients (AC, JA, AW) experienced a relapse of symptoms three to seven weeks after the papillotomy. At control manometry a residual sphincter activity was found in all three; Blp values were: AC $30 \mathrm{mmHg}$, JA $28 \mathrm{mmHg}$ and AW $30 \mathrm{mmHg}$. The following ERCP revealed a biliary tree identical to that found at the first investigation. These patients were submitted to repapillotomy which resulted in a relief of symptoms during the follow up period of 11-16 months.

One patient (MJ) experienced a relapse of symptoms 14 months after papillotomy. Her present symptoms are far less severe, however, and less distinct. Re-examination by ERCP did not show any restenosis. There was no dilatation of the bile duct and there was rapid drainage of the contrast medium. Manometry showed the choledochoduodenal gradient to be zero, absent sphincter phasic activity and no pressure increase after a cholecystokinin injection, which was accompanied by a moderate and short lasting abdominal pain with no distinct characteristics.

\section{Discussion}

Recently Hogan et $a l^{1}$ described a paradoxical response of sphincter of Oddi to intravenous injection of cholecystokinin in five of 38 patients with suspected sphincter of Oddi dysfunction. After completion of our study an additional paper ${ }^{6}$ was published in which 10 of 32 subjects thought to suffer from biliary dyskinesia exhibited paradoxical response to intravenous injection of cholecystokinin. Our study confirms that cholecystokinin which normally produces an inhibition of the sphincter of Oddi may cause a paradoxical increase of the sphincter of Oddi activity. Furthermore we found that such a response may also occur after intravenous injection of ceruletide which has not been earlier reported.

Some differences in manometric findings in our study in comparison with the two others ${ }^{16}$ may be worth mentioning. In our study increase of the basal sphincter of Oddi pressure was the most frequent finding. The response was most pronounced during the first minute of the intravenous injection, which is in accordance with earlier findings. 'In that study, however, the paradoxical response was observed exclusively in patients with raised prestimulatory sphincter of Oddi pressure, while in our paper five of the patients with paradoxical response had normal prestimulatory values. In the other study ${ }^{6}$ the predominant feature observed was an increase in 
frequency of phasic contractions. None of the patients included in our study showed such a response. The differences in manometric findings might be because of the different criteria for selecting patients for endoscopic manometry. Our patients were investigated on the clinical suspicion of biliary dyskinesia and they all had normal liver tests and ERCP. The patients studied by Hogan et $a l^{1}$ and Toouli et al had had not only clinical symptoms, but also abnormal liver tests and/or radiological findings of delayed bile duct drainage. Furthermore there is also a possibility that the relative rarity of the biliary dyskinesia limits the chance of various manometric features to be exposed. In fact after the completion of our study we have observed a patient in whom the intravenous injection of cholecystokinin resulted in an increase of frequency of phasic contractions (4-16/minute) accompanied by a rise of Blp and clinically by biliary type of pain. A papillotomy was carried out and the patient was relieved of pain.

It might be argued that the observed increase in sphincter of Oddi pressure could be an artefact-for example, pain which often accompanied the hormone injection could cause an increase of the intraabdominal pressure due to voluntary strain. This seems unlikely, however, as the duodenal Blp remained unchanged. The abnormal sphincter of Oddi pressure after hormone stimulation could be explained by a defective function of non-adrenergic, non-cholinergic neurones. These normally mediate the inhibitory effect of cholecystokinin on the sphincter muscle, thus overriding its direct stimulatory effect on the sphincter. ${ }^{7}$

The results of the therapeutic intervention in patients with a paradoxical sphincter of Oddi response to cholecystokinin or ceruletide have not earlier been reported. Eight of our patients have had a papillotomy (and repapillotomy in four) or balloon dilatation with pain relief or marked improvement in all. Although one patient relapsed 14 months after the intervention the therapeutic effect was lasting in the remaining patients during an observation period of 11-16 months. We consider this as a satisfactory result in these patients who had had a right upper quadrant pain over a very long period. As the present study was not placebo controlled, however, the number of patients is fairly small and the observation time relatively short, our results have to be considered as preliminary.

It has been reported recently that the pain relieving effect of intravenous injection of caerulein in patients with biliary colic ${ }^{8}$ could be ascribed to the relaxing effect of the hormone on sphincter of Oddi. As shown in this study, sphincter of Oddi might respond paradoxically in some patients and thus aggravate the symptoms, and therefore caerulein should be used with caution in patients with biliary pain.

\section{References}

1 Hogan W, Geenen J, Dodds W, Toouli J, Venu R, Helm J. Paradoxical motor response to cholecystokinin (CCK-OP) in patients with suspected sphincter of Oddi dysfunction. Gastroenterology 1982; 82: 1085 .

2 Toouli J, Hogan WJ, Geenen JE, Dodds WJ, Arndorfer RC. Action of cholecystokinin-octapeptide on sphincter of Oddi basal pressure and phasic wave activity in humans. Surgery 1982; 92: 497-503.

3 Corazziari E, DeMasi E, Gatti V et al. Caerulein and sphincter of Oddi pressure activity. Ital J Gastroenterol 1982; 14: 239-41.

4 Ganzina F, Santamaria A. Cacrulein (ceruletide). A review. Acta Gastroenterol Belg 1976; 39: 169-85.

5 Funch-Jensen P. Diederich P, Kraglund K. Intraoperative sphincter of Oddi manometry in patients with gallstones. Scand J Gastroenterol 1984; 19: 931-36.

6 Toouli J. Roberts-Thomsom IC, Dent J, Lee J. Manometric disorders in patients with suspected sphincter of Oddi dysfunction. Gastroenterology 1985; 88: $1243-5()$.

7 Toouli J. Sphincter of Oddi motility. Br J Surg 1984; 71: $251-56$

8 Basso N, Bagarani M, Materia A et al. Effects of caerulein in patients with biliary colic pain. Gastroenterology 1985; 89: 605-9. 